\title{
Gambaran Kebiasaan Menyikat Gigi dan Status Kesehatan Gingiva pada Anak Sekolah Dasar
}

\author{
Novia D. P. Rasni, ${ }^{1}$ Johanna A. Khoman, ${ }^{1}$ Damajanty H. C. Pangemanan ${ }^{2}$
}

\author{
${ }^{1}$ Program Studi Pendidikan Dokter Gigi Fakultas Kedokteran Universitas Sam Ratulangi \\ Manado \\ ${ }^{2}$ Bagian Fisiologi Fakultas Kedokteran Universitas Sam Ratulangi Manado \\ Email: vivirasni27@gmail.com
}

\begin{abstract}
Besides caries, tooth and mouth disease commonly found in children is gingival inflammation (gingivitis). The high prevalence of gingivitis in Indonesia is due to the fact that most people have not adopted good and effective habits in tooth brushing. Indicators determining the effectiveness of tooth brushing consist of tooth brushing time, frequency, duration, and method. This study was aimed to determine the overview of tooth brushing habit and gingival health status among elementary school students. This was a literature review study using the Google Scholar database. The keywords used were brushing habits, gingival health status, and elementary school children. Based on the inclusion and exclusion criteria, a critical appraisal was carried out that obtained 4 literatures consisting of 2 cross-sectional studies and 2 descriptive surveys. The results showed that most children had good habit of tooth brushing, however there were some children who had poor habit tooth brushing due to lack of understanding about the time, method, duration, and frequency of tooth brushing. The most common gingival disease was categorized as mild inflammation, followed by moderate inflammation; no severe inflammation criteria was reported. In conclusion, most elementary school students had good habit of tooth brushing and the most common gingival disease was in mild inflammation.
\end{abstract}

Keywords: habit of brushing teeth, gingival health status, and elementary school children.

\begin{abstract}
Abstrak: Penyakit gigi dan mulut yang banyak ditemukan pada anak selain karies ialah peradangan gingiva (gingivitis). Tingginya prevalensi gingivitis di Indonesia disebabkan karena masyarakat belum menerapkan kebiasaan yang baik dan efektif dalam menyikat gigi. Indikator penentu efektivitas menyikat gigi terdiri dari waktu menyikat gigi, frekuensi, durasi, dan metode. Penelitian ini bertujuan untuk mengetahui gambaran kebiasaan menyikat gigi dan status kesehatan gingiva pada anak Sekolah Dasar. Jenis penelitian ialah studi pustaka. Pencarian data menggunakan database Google Scholar. Kata kunci yang digunakan yaitu kebiasaan menyikat gigi, status kesehatan gingiva, dan anak sekolah dasar. Setelah diseleksi berdasarkan kriteria inklusi dan eksklusi, dilakukan critical appraisal dan didapatkan 4 pustaka terdiri dari 2 studi potong lintang dan 2 survei deskriptif. Hasil penelitian mendapatkan sebagian besar anak melakukan kebiasaan menyikat gigi dengan baik namun masih terdapat anak dengan kebiasaan menyikat gigi yang buruk akibat kurangnya pengertian mengenai waktu menyikat gigi, frekuensi, durasi, dan metode. Penyakit gingiva yang paling banyak didapatkan yaitu pada kriteria inflamasi ringan, diikuti kriteria inflamasi sedang; kriteria inflamasi berat tidak dilaporkan. Simpulan penelitian ini ialah sebagian besar anak Sekolah Dasar telah melakukan kebiasaan menyikat gigi yang baik dan penyakit gingiva yang tersering ditemukan pada kriteria inflamasi ringan.
\end{abstract}

Kata kunci: kebiasaan menyikat gigi, status kesehatan gingiva, dan anak sekolah dasar

\section{PENDAHULUAN}

Kesehatan gigi dan mulut masyarakat Indonesia masih merupakan hal yang perlu mendapat perhatian serius dari tenaga kesehatan, baik dokter gigi maupun perawat 
gigi. ${ }^{1}$ Riset Kesehatan Dasar (RISKESDAS) tahun 2018 menyatakan bahwa sebanyak $57,6 \%$ masyarakat Indonesia memiliki permasalahan kesehatan gigi dan mulut. ${ }^{2}$ Berdasarkan teori Blum, status kesehatan gigi dan mulut seseorang atau masyarakat dipengaruhi oleh empat faktor yaitu keturunan, lingkungan, perilaku, dan pelayanan kesehatan. Perilaku memegang peranan penting dalam memengaruhi status kesehatan gigi dan mulut. ${ }^{3}$

Secara umum perilaku kesehatan adalah semua aktivitas seseorang baik yang dapat diamati maupun tidak dapat diamati yang berkaitan dengan pemeliharaan dan peningkatan kesehatan. ${ }^{4}$ Salah satu perilaku hidup sehat yaitu menyikat gigi. Perilaku yang benar dalam menyikat gigi mengacu pada Federation Dentaire Internationale (FDI) adalah kebiasaan menyikat gigi setiap hari, minimal dua kali sehari, sesudah sarapan pagi dan sebelum tidur malam. Adapun perilaku menyikat gigi yang benar pada masyarakat Indonesia masih sangat rendah $2,8 \%{ }^{2}$ Gigi yang tidak dibersihkan dapat menyebabkan penimbunan sisa makanan yang dapat berdampak pada menurunnya status kesehatan gingiva.

Gingiva ialah bagian mukosa rongga mulut yang mengelilingi gigi dan menutupi alveolar ridge, dan berfungsi melindungi jaringan di bawah perlekatan gigi terhadap pengaruh lingkungan rongga mulut. ${ }^{5}$ Berdasarkan data RISKESDAS pada tahun 2018, proporsi masalah kesehatan mulut di Indonesia menurut karakteristik gingiva bengkak $14,0 \%$ dan gingiva mudah berdarah $13,9 \%$. $^{2}$

Masalah kebersihan gigi dan mulut serta gingiva sering terjadi pada anak usia 12-15 tahun. World Health Organization (WHO) merekomendasikan untuk melakukan kajian-kajian epidemiologi kesehatan gigi dan mulut pada kelompok usia 12-15 tahun, yang merupakan usia kritis pengukuran indikator penyakit periodontal anak untuk pemeriksaan karena gigi tetap yang menjadi indeks penelitian telah seutuhnya bertumbuh. ${ }^{6}$ Beberapa studi epidemiologi menunjukkan bahwa kebersihan gigi dan mulut serta status gingiva dari berbagai tingkat keparahan pada umumnya ditemukan pada anak dan remaja. ${ }^{7,8}$ Penelitian yang dilakukan oleh Fitri ${ }^{9}$ pada anak Sekolah Dasar menyatakan bahwa kebiasaan menyikat gigi memengaruhi status kesehatan gingiva.

Mengingat penyakit yang dapat timbul pada gingiva yang tidak dirawat, maka peneliti tertarik untuk meneliti gambaran kebiasaan menyikat gigi dan status kesehatan gingiva pada anak Sekolah Dasar.

\section{METODE PENELITIAN}

Penelitian ini dilaksanakan pada bulan Mei-Juli 2020 di perpustakaan virtual. Jenis penelitian ini ialah studi pustaka (literature review). Populasi dalam penelitian ini yaitu seluruh jurnal dan artikel yang diperoleh dari database Google scholar. Instrumen yang digunakan dalam penelitian ini yaitu The Joanna Briggs Institute (JBI) Critical Appraisal. Isi instrumen penelitian berupa daftar penilaian The JBI Critical Appraisal yang tersedia dalam bentuk checklist dimana setiap pertanyaan akan dinilai berdasarkan kriteria dan diberi nilai 'ya', 'tidak', 'tidak jelas', atau'tidak berlaku'. Setiap skor 'ya' diberi satu poin dan nilai lainnya ialah nol. Hasil akhir penilaian studi dilihat dari jumlah skor yang didapatkan dan harus mencapai 50\% agar studi terhitung dalam literature review. Pada penelitian ini, artikel yang telah memenuhi kriteria inklusi dan eklusi serta kelayakan telah teruji berjumlah 4 artikel, terdiri dari 2 studi potong lintang dan 2 survei deskriptif.

\section{HASIL PENELITIAN}

Empat artikel memenuhi kriteria inklusi dan eksklusi dalam studi literatur ini. Keempat artikel tersebut membahas variabel keduanya. Faktor yang berkontribusi dalam studi kebiasaan menyikat gigi dengan status kesehatan gingiva sebagian besar merupakan studi potong lintang dan deskriptif dengan jumlah rerata peserta kurang lebih 100 orang. Tabel 1 memperlihatkan karakteristik keempat artikel yang dipakai dalam penelitian ini. 
Tabel 1. Karakteristik jurnal berdasarkan peneliti, tahun, metode, populasi, dan ringkasan hasil

\begin{tabular}{|c|c|c|c|}
\hline $\begin{array}{c}\text { Penulis dan } \\
\text { Tahun }\end{array}$ & Judul & $\begin{array}{l}\text { Metode dan } \\
\text { Populasi }\end{array}$ & Ringkasan hasil \\
\hline Fitri, 20199 & $\begin{array}{l}\text { Pengaruh kebiasaan menyikat } \\
\text { gigi sebelum tidur malam hari } \\
\text { terhadap status gingiva pada } \\
\text { siswa SDN 08 Parak Gadang } \\
\text { Barat Kelas IV dan V }\end{array}$ & $\begin{array}{l}\text { Metode potong } \\
\text { lintang } \\
\text { Populasi: } 34 \text { anak }\end{array}$ & $\begin{array}{l}\text { Berdasarkan hasil penelitian, } \\
\text { didapatkan } 55,9 \% \text { responden } \\
\text { mengalami gingivitis ringan } \\
\text { dan 52,9\% responden memiliki } \\
\text { kebiasaan tidak teratur menyi- } \\
\text { kat gigi malam sebelum tidur }\end{array}$ \\
\hline $\begin{array}{l}\text { Maruanaya et } \\
\text { al, } 2015^{10}\end{array}$ & $\begin{array}{l}\text { Gambaran status gingiva } \\
\text { menurut kebiasaan menyikat } \\
\text { gigi sebelum tidur malam hari } \\
\text { pada siswa Sekolah Dasar } \\
\text { Negeri } 70 \text { Manado }\end{array}$ & $\begin{array}{l}\text { Metode deskriptif } \\
\text { Populasi: } 45 \text { anak }\end{array}$ & $\begin{array}{l}\text { Hasil penelitian menunjukkan } \\
\text { bahwa berdasarkan pengukuran } \\
\text { indeks gingiva sebagian besar } \\
\text { siswa-siswi memiliki status } \\
\text { gingiva dengan kriteria infla- } \\
\text { masi ringan }(55,6 \%) \text {. Untuk } \\
\text { status gingiva berdasarkan } \\
\text { menyikat gigi sebelum tidur } \\
\text { malam hari diperoleh hasil } \\
\text { bahwa sebagian besar siswa- } \\
\text { siswi ( } 55,6 \%) \text { menyikat gigi } \\
\text { sebelum tidur malam hari. }\end{array}$ \\
\hline $\begin{array}{l}\text { Mareta, } \\
2018^{11}\end{array}$ & $\begin{array}{l}\text { Hubungan kebiasaan menyi- } \\
\text { kat gigi dengan status peri- } \\
\text { odontal pada pasien anak usia } \\
6-12 \text { tahun di Poliklinik } \\
\text { IKGA RSGM UNAIR }\end{array}$ & $\begin{array}{l}\text { Metode observasio- } \\
\text { nal dengan desain } \\
\text { potong lintang }\end{array}$ & $\begin{array}{l}\text { Terdapat hubungan yang signi- } \\
\text { fikan antara kebiasaan menyi- } \\
\text { kat gigi dan status periodontal } \\
\text { pada pasien anak usia } 6-12 \\
\text { tahun di poliklinik IKGA } \\
\text { RSGM UNAIR }\end{array}$ \\
\hline Iqbal, $2011^{12}$ & $\begin{array}{l}\text { Distribusi frekuensi gingivitis } \\
\text { dan kebiasaan menyikat gigi } \\
\text { murid SDN } 22 \text { usia } 7-9 \text { tahun } \\
\text { Kecamatan Baiturrahman } \\
\text { Banda Aceh }\end{array}$ & $\begin{array}{l}\text { Metode survei } \\
\text { deskriptif } \\
\text { Populasi: } 97 \text { anak }\end{array}$ & $\begin{array}{l}\text { Hasil penelitian ini menunjuk- } \\
\text { kan bahwa keadaan gingiva } \\
\text { murid SDN } 22 \text { usia } 7-9 \text { tahun } \\
\text { Kecamatan Baiturrahman Ban- } \\
\text { da Aceh rata-rata sehat. }\end{array}$ \\
\hline
\end{tabular}

\section{BAHASAN}

Penelitian oleh Fitri ${ }^{9}$ yang dilakukan pada 34 anak menyatakan bahwa status gingiva dapat diukur berdasarkan faktor kebiasaan menyikat gigi sebelum tidur malam hari. Berdasarkan faktor tersebut diperoleh responden yang menderita gingivitis ringan $(50,9 \%)$ dan yang memiliki status gingiva normal $(44,1 \%) .{ }^{9}$ Mareta $^{11}$ dalam penelitiannya mengemukakan terdapat korelasi bermakna $(p=0,029)$ antara kebiasaan menyikat gigi dengan status periodontal PI dan GI.

Hasil penelitian Iqbal $^{12}$ yang dilakukan pada 97 subyek mendapatkan 72 murid $(74,22 \%)$ mempunyai gingiva sehat dan 25 murid $(25,78 \%)$ yang mengalami gingivitis. Gingivitis dengan frekuensi menyikat gigi 1 kali sehari merupakan jumlah terbesar yaitu sebanyak 15 murid (60\%). Gingivitis yang terjadi pada subjek yang menyikat gigi selain pada waktu setelah sarapan atau sebelum tidur merupakan jumlah terbesar yaitu sebanyak 18 murid (72\%). Gingivitis yang terjadi pada subjek dengan cara menyikat gigi metode maju mundur merupakan jumlah terbesar yaitu sebanyak 21 murid (84\%).

Penelitian Maruanaya dan Mariati ${ }^{10}$ menunjukkan sebagian besar responden $(73,3 \%)$ menyikat gigi dengan menggunakan metode kombinasi, sebanyak 48,9\% siswa-siswi menyikat gigi kurang dari 2 menit, dan sebagian besar responden $(75,6 \%)$ menyikat gigi 2 kali sehari. Data hasil penelitian status gingiva dari 45 subjek 
penelitian mendapatkan 4 siswa $(8,9 \%)$ yang memiliki status gingiva dengan kriteria normal, 25 siswa $(55,6 \%)$ dengan kriteria inflamasi ringan, dan 16 siswa $(35,5 \%)$ dengan kriteria inflamasi sedang. Tidak terdapat siswa $(0 \%)$ yang memiliki status gingiva dengan kriteria inflamasi berat. Hal ini dipengaruhi oleh metode menyikat gigi. Metode kombinasi merupakan metode gabungan antara beberapa gerakan dalam menyikat gigi antara lain gerakan horizontal, vertikal, dan sirkular. Kombinasi metode sirkular, horizontal, dan vertikal merupakan cara menyikat gigi yang paling efektif. ${ }^{13}$

Selain metode menyikat gigi, hal penting lainnya yang harus diperhatikan ialah durasi menyikat gigi. Lama menyikat gigi tidak ditentukan, tetapi biasanya dianjurkan minimal 2 menit dan maksimal 5 menit. Yang penting dilakukan secara sistematik supaya tidak ada bagian-bagian yang terlampaui. ${ }^{14}$

Efektivitas menyikat gigi selain ditentukan oleh faktor yang telah dipaparkan, juga ditentukan oleh frekuensi dan waktu menyikat gigi. Menyikat gigi 2 kali sehari sudah cukup, karena pembersihan sisa makanan kadang-kadang tidak sempurna, dan terdapat kemungkinan bahwa bila ada yang terlewat pada pagi hari, waktu malam hari masih dapat dibersihkan. Waktu terpenting menyikat gigi ialah yang terakhir malam hari sebelum tidur, karena aliran air ludah tidak seaktif siang hari sehingga bakteri berkembang biak dari sisa makanan. Menyikat gigi pertama kali dilakukan pagi hari karena bakteri berkumpul dalam mulut. ${ }^{15}$

Kebiasaan menyikat gigi yang baik memang dapat turut mencegah terjadinya gingivitis karena gigi menjadi bersih dari sisa-sisa makanan, bakteri, dan plak. Gigi sebaiknya disikat pagi setelah sarapan, dan malam sebelum tidur. Pada malam hari, khususnya saat waktu tidur, jumlah cairan liur manusia cenderung menurun, akibatnya mulut menjadi kering, proses penetralan plak tidak berlangsung secara optimal, dan dapat menyebabkan gingivitis.

\section{SIMPULAN}

Sebagian besar anak Sekolah Dasar melakukan kebiasaan menyikat gigi dengan baik. Penyakit gingiva yang paling banyak didapatkan pada kriteria inflamasi ringan.

\section{Konflik Kepentingan}

Penulis menyatakan tidak terdapat konflik kepentingan dalam studi ini.

\section{DAFTAR PUSTAKA}

1. Haryanti DD, Adhani R, Aspriyanto D, Dewi I R. Efektifitas meyikat gigi metode horizontal, vertical, dan roll terhadap penurunan plak pada anak usia 9-11 tahun. Dentino. 2014;2(2):150-4.

2. Badan Penelitian dan Pengembangan Kesehatan. Hasil utama Riskesdas 2018. Jakarta: Kemenkes RI, 2018; p. 195, 217.

3. Notoatmodjo S. Pendidikan dan Perilaku Kesehatan (1st ed). Jakarta: Rineka Cipta, 2003; p.5- 8.

4. Linasari, Meilenra K. Hubungan prilaku menyikat gigi pada malam hari dengan tingkat keparahan gingivitis pada remaja di Bandar Lampung. Jurnal Ilmiah Keperawatan Sei Batik. 2018;14(2):200-4.

5. Manson DJ, Eley MB. Buku Ajar Periodonti (2nd ed). Jakarta: Penerbit Hipokrates,1993; p.1-19, 150.

6. World Health Organization. Important target groups. [online] 2013 [cited 2015 April 16]. Available from: URL: http://www. who.

7. Chauan VS, Chauan RS, Devkar N, Vibhute A, More S. Gingival and periodontal disease in children and adolescents. $\mathrm{J}$ Dent Allied Sci. 2012;1(1):26-9.

8. Basuni, Cholil. D, Kania P. Gambaran indeks kebersihan mulut berdasarkan tingkat pendidikan masyarakat di desa Guntung Ujung Kabupaten Banjar. Dentino. 2014;2(1):18-23.

9. Fitri AN. Pengaruh Kebiasaan Menyikat gigi Sebelum Tidur Malam Hari terhadap Status Gingiva pada Sisawa SDN 08 Parak Gadang Barat Kelas IV dan V [Skripsi]. Padang: Fakultas Kedokteran Gigi Universitas Andalas; 2019.

10. Maruanaya AM, Mariati NW, Pangemanan DHC. Gambaran status gingiva menurut kebiasaan menyikat gigi sebelum tidur malam hari pada siswa Sekolah Dasar 
Negeri 70 Manado. e-GiGi. 2015;3(2): 247-9.

11. Mareta I. Hubungan kebiasaan menyikat gigi dengan periodontal pada pasien anak usia 6-12 tahun di Poliklinik IKGA RSGM UNAIR. Surabaya: Perpustakaan Universitas Airlangga, 2018. Available from: http://repository. unair. ac.id/68730/

12. Iqbal M. Distribusi frekuensi gingivitis dan kebiasaan menyikat gigi Murid SDN 22 usia 7-9 tahun Banda Aceh [Skripsi]. Banda Aceh: Fakultas Kedokteran. Universitas Syiah Kuala Darussalam; 2011.

13. Scottish Intercollegiate Guidelines Network SIGN A National Clinical Guideline December 2000 Preventing Dental Caries in Children at High
Caries Risk. A National Clinical Guideline [serial online]. 2000;47:8. [cited 2012 Mar 12]. Available from: URL: http:www.sign.ac. uk/pdf/sign47. pdf.

14. Hidayat R. Kesehatan Gigi dan Mulut-Apa yang Sebaiknya Anda Tahu? (1st ed). Yogyakarta: Andi, 2016.

15. Fatarina NF. Hubungan antara frekuensi menggosok gigi, cara menggosok gigi, dan bentuk sikat gigi dengan status kebersihan gigi dan mulut pada siswa kelas IV dan V SDN Karangroto 04 Kecamatan Genuk Kota Semarang tahun 2007. 2010. [cited 2020 Mar 12]. Available from digilib.unimus.ac.id/ files/disk1/105/jtptunimus-gdlnurfaizahf-5210-3-bab2.pdf 